\title{
Freezing and thawing resistance of internally cured high performance concrete
}

\author{
Muthana Saadi ${ }^{1, *}$, Tareq al-Attar ${ }^{2}$, and Shatha Hasan $^{2}$ \\ ${ }^{1}$ Ministry of Planning, Baghdad, Iraq \\ ${ }^{2}$ University of Technology, Baghdad, Iraq
}

\begin{abstract}
The behavior of internally cured high performance concrete, HPC, exposed to freezing and thawing cycles, was investigated. Two saturated curing agents, Limestone dust and powder of Porcelanite rock, were used to facilitate internal curing for concrete. These agents were used as partial replacements of fine aggregate in two volumetric percentages, 20 and 30 percent. The cast concrete specimens were separated in two groups according to curing method: water-cured and sealed (only internally-cured) specimens. The concrete specimens were subjected to three exposure systems, $\mathrm{F}_{0}$ : without freezing and thawing, and $\mathrm{F}_{1}$ and $\mathrm{F}_{2}$ : with 50 and 100 cycles of freezing and thawing, respectively. The freezing and thawing test was done as stipulated by the ASTM C666. The conducted tests for each exposure were: compressive and flexural strengths. The results revealed that internal curing does not enhance the concrete resistance to freezing and thawing cycles. Using saturated agents has increased the moisture content of concrete and makes it more vulnerable to frost action deterioration. Sealed specimens for all investigated mixes showed lower reductions in strength than water-cured ones. The lesser water content of these mixes may be the reason for that behavior.
\end{abstract}

\section{Introduction}

Cyclic freezing and thawing deterioration is known to be the major source of deterioration of concrete in most of the places experiencing severe cold weather. The extent of the problem can be appreciated from the fact that almost one-third of all concrete poured in Nordic European countries is susceptible to freezing and thawing deterioration [1]. Infrastructures in northern Japan have also suffered extensively due to this phenomenon [2]. Damage due to freezing and thawing deterioration can take various forms, the most common being scaling and micro-cracking [3]. Both these forms of damage are known to potentially progress individually within the same structural member [4].

Other forms of damage may include large-scale spalling and crumbling of concrete and crossing fatigue-like cracks visible on the surface. All these symptoms are generally accompanied by loss in strength and serviceability of concrete. Scaling is a surface phenomenon and is usually responsible for the wearing off of the outer few millimeters of concrete. Light scaling can cause concrete surfaces to become rough, and more severe scaling can expose coarse aggregate, sometimes even scaling off more than $10 \mathrm{~mm}$ of cover concrete. It has been found that processes like improper troweling, insufficient curing and bleeding lead to the formation of a highly porous zone of concrete near the surface that is much more susceptible to scaling [5].
Though its mechanism isn't very clear yet, the use of deicing salt, generally used to remove snow from pavements, bridge decks, runways, sidewalks is generally held responsible for intensified and faster scaling of concrete surface, especially in concretes with low air contents. Tensile pressures generated within concrete, during cyclic freezing and thawing, are known to generate cracks within concrete, reducing its strength and integrity. Microscopic studies verify the growth of around $1-10 \mu \mathrm{m}$ wide micro-cracks upon subjecting concrete to freezing and thawing cycles. These cracks have been found to pass through cement paste and follow the boundaries of most large aggregate particles [6].

Many factors are found to affect the propagation of micro-cracks within concrete, with air-entrainment, water/cement ratio and strength. Curing and saturation are believed to have major influences on durability of high performance concrete when exposed to freezing and thawing cycles.

\section{Experimental work}

\subsection{Materials and concrete mix}

The cement used throughout this investigation is sulfate resisting Portland cement. Test results showed that the cement conforms to the provisions of Iraqi Standard IQS 5/1984- Type V [7]. Natural sand with fineness modulus 
of 3.19 was used as fine aggregate. The coarse aggregate was crushed gravel with maximum size of $19 \mathrm{~mm}$. The grading and sulfate content of both used aggregates are conforming to the provisions of the Iraqi Standard IQS 45/1984[8]. Silica fume conforming to the ASTM C1240 [9] was the used supplementary cementitious material throughout this investigation. It has a specific surface of $20 \mathrm{~m}^{2} / \mathrm{g}$.

Porcelanite and limestone dust were adopted as internal curing agents. They were graded as the fine aggregate and used as partial replacement for fine aggregate in 20 and $30 \%$ by volume.

Many trial mixes were done in this work to obtain an average required compressive strength, $f_{c u}$, at 28 days equals to $60 \mathrm{MPa}$. The weight proportions of the chosen mix were: 1: 1.4: 1.9: 0.25 (binder: fine aggregate: coarse aggregate: $\mathrm{W} / \mathrm{CM}$ ratio). The total binder content was $500 \mathrm{~kg} / \mathrm{m}^{3}$.

Five mixes were produced to investigate the effect internal curing agents, limestone dust and Porcelanite, on resistance to freezing and thawing. These mixes were:

$\mathrm{M}_{0}$ : reference mix made without fine aggregate replacement.

$\mathrm{M}_{20 \mathrm{~L}}$ : a mix made with $20 \%$ fine aggregate replacement by limestone dust.

$\mathrm{M}_{30 \mathrm{~L}}$ : a mix made with $30 \%$ fine aggregate replacement by limestone dust.

$\mathrm{M}_{20 \mathrm{P}}$ : a mix made with $20 \%$ fine aggregate replacement by Porcelanite.

$\mathrm{M}_{30 \mathrm{P}}$ : a mix made with $30 \%$ fine aggregate replacement by Porcelanite.

\subsection{Curing procedures}

After casting and demolding of concrete specimens, two curing procedures were adopted. In the first; the specimens were completely immersed in tap water until the time of testing (water-cured specimens denoted with w letter). The curing water was replaced at least once a month. Second method of curing is to put the specimens in plastic bags and prevent any water to penetrate the bags (sealed specimens denoted with $\mathbf{s}$ letter). The second method was done to illustrate the impact of internal curing on the behavior of tested specimens.

\subsection{Freezing and thawing exposure}

The freezing and thawing test was carried out according to ASTM C666-08[10].The exposure conditions were as fallow:

1. F0: mixes were not exposed to freezing and thawing cycles.

2. F1: mixes were exposed to 50 cycles of freezing and thawing.

3. F2: mixes were exposed to 100 cycles of freezing and thawing.

According to the above mentioned standard method of test the specimens were cubes $(100 \times 100 \times 100) \mathrm{mm}$ and prisms $(100 \times 100 \times 400) \mathrm{mm}$. They were put in the test chamber at the age of 14 days. Specimens in the pre-test period were kept in water for water-cured specimens and in plastic bags for sealed specimens.

The compressive strength test was considered as an indication for concrete resistance to the above described exposure conditions. This test was carried out according to the BS EN 12390 [11] for cubes with dimensions of $(100 \times 100 \times 100) \mathrm{mm}$ at ages of 14,28 and 60 days. white, and this should be taken into account when preparing them.

\section{Results and discussions}

Table 1 displays the effect of different freezing and thawing exposures on compressive strength of the studied concrete mixes. Figure 1 shows the compressive strength variations of mix $\mathrm{M}_{0}$ for both water-cured and sealed specimens when being exposed to different freezing and thawing exposures. It could be observed that the rate of gain (or reduction) in strength is almost the same (the lines are almost parallel). This behavior may be a result of that the two groups of specimens have suffered the same exposure conditions. The only difference between them is that the water-cured group has been in water till the ages of 14 days; meanwhile the second group was kept in bags from the date of casting till the age of test. This difference seems to have no effect on later behavior, especially if one keeps in mind the low permeability characteristic of studied concrete.

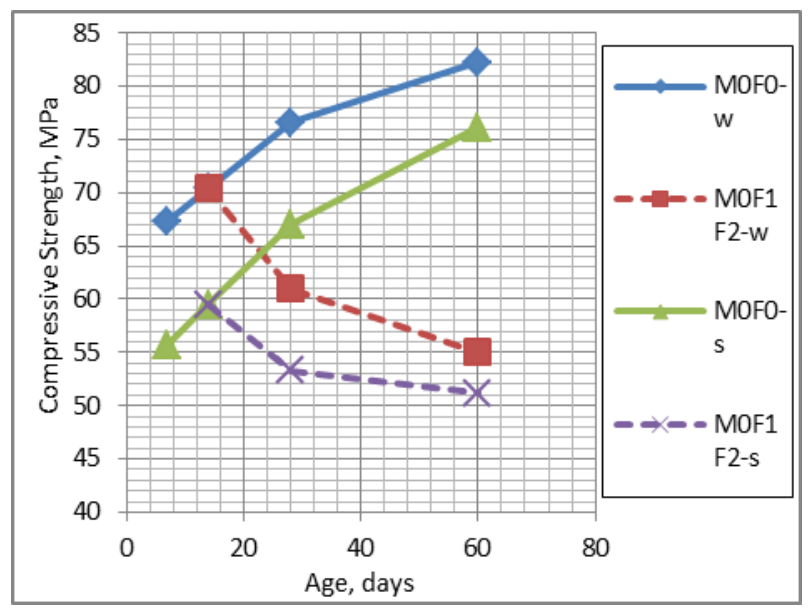

Fig. 1. Compressive strength variations of mix $M_{0}$ for both water-cured and sealed specimens when being exposed to different freezing and thawing exposures

Figures 2 and 3 illustrate the effect of replacement of fine aggregate by Limestone dust on concrete resistance to freezing and thawing cycles for water-cured and sealed specimens, respectively. The use of saturated Limestone dust has adversely affected the compressive strength and the reduction in strength increased with the increased replacement percentage and increased number of freezing and thawing cycles. It is worthy to note that when the divergence between the solid and dotted lines, of the same mix and at the same age, increases it means the reduction in compressive strength will increase. 


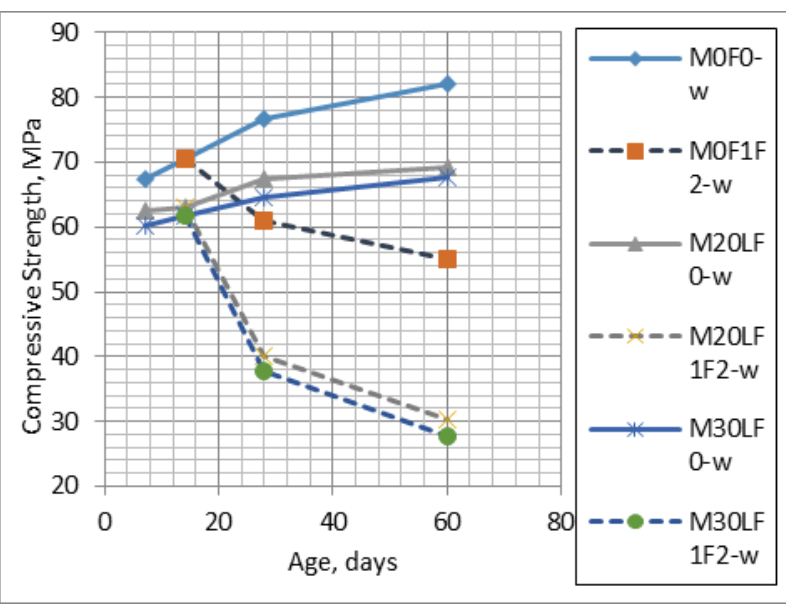

Fig. 2. Compressive strength variations of mixes $M_{0}, M_{20 L}$ and $\mathrm{M}_{30 \mathrm{~L}}$ for water-cured specimens when being exposed to different freezing and thawing exposures

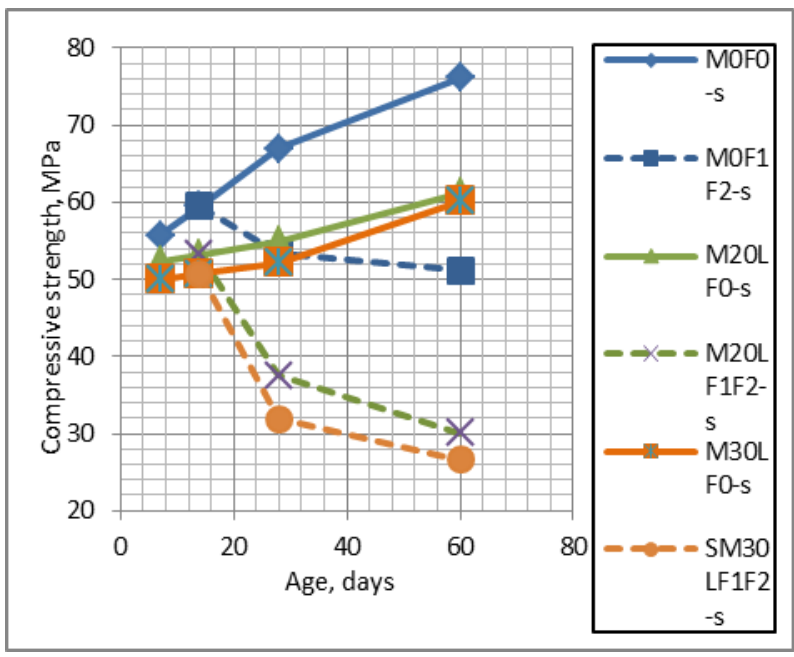

Fig. 3. Compressive strength variations of mixes $\mathrm{M}_{0}, \mathrm{M}_{20 \mathrm{~L}}$ and $\mathrm{M}_{30 \mathrm{~L}}$ for sealed specimens when being exposed to different freezing and thawing exposures

For water-cured mix $\mathrm{M}_{20 \mathrm{~L}}$, when making comparisons between F0, F1 and F2, the reductions in strength will be 41 and 56 percent for 50 and 100 cycles, respectively. And for 30 percent replacement, mix $\mathrm{M}_{30 \mathrm{~L}}$; these reductions will be 42 and 59 percent for 50 and 100 cycles, respectively. Moreover, when making comparisons between mixes $\mathrm{M}_{0}$ and $\mathrm{M}_{20 \mathrm{~L}}$, the reductions in compressive strength will be 34 and 45 percent for 50 and 100 cycles, respectively. For mixes $\mathrm{M}_{0}$ andM $\mathrm{M}_{30 \mathrm{~L}}$; these reductions will be 38 and 49 percent for 50 and 100 cycles, respectively.

These results could reveal the following conclusions:

a. The two adopted replacement percentages have the same effect in magnitude on concrete durability and cause almost the same degradation in compressive strength.

b. The extra carbonation bond between limestone and cement paste could create a saturated stiff matrix with low permeability. This situation prevents the water to escape and to exert higher pressure on pore walls leading to more microcracking and more strength reduction [12].
Sealed specimens for the same mentioned mixes, $M_{20 L}$ and $\mathrm{M}_{30 \mathrm{~L}}$, showed lower reductions in strength than water-cured ones. The lesser water contents of these mixes may be the reason for that behavior [13].

Figures 4 and 5 display the behavior of mixes $\mathrm{M}_{20 \mathrm{P}}$ and $\mathrm{M}_{30 \mathrm{P}}$ when being exposed to freezing and thawing cycles for water-cured and sealed specimens, respectively. For water-cured specimens, using saturated Porcelanite has negatively affected the compressive strength and the reduction in strength was negatively proportioned to the replacement percentage and positively proportioned to the number of freezing and thawing cycles. On contrast to that, for sealed specimens the reduction in compressive strength increased with the increased replacement percentage and increased number of freezing and thawing cycles. Sealed specimens showed lower reductions in strength than water-cured ones. The lesser water contents of these mixes may be the reason for that behavior.

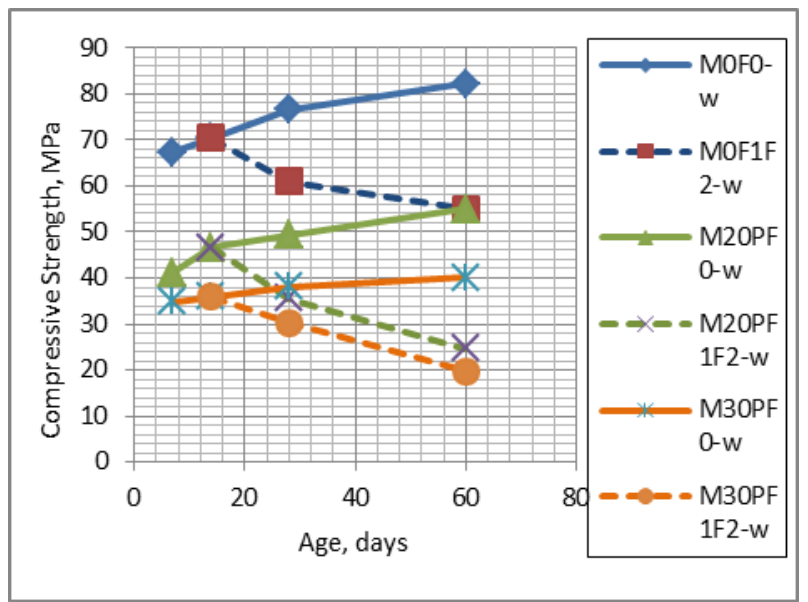

Fig. 4. Compressive strength variations of mixes $\mathrm{M}_{0}, \mathrm{M}_{20 \mathrm{P}}$ and $\mathrm{M}_{30 \mathrm{P}}$ for water-cured specimens when being exposed to different freezing and thawing exposures

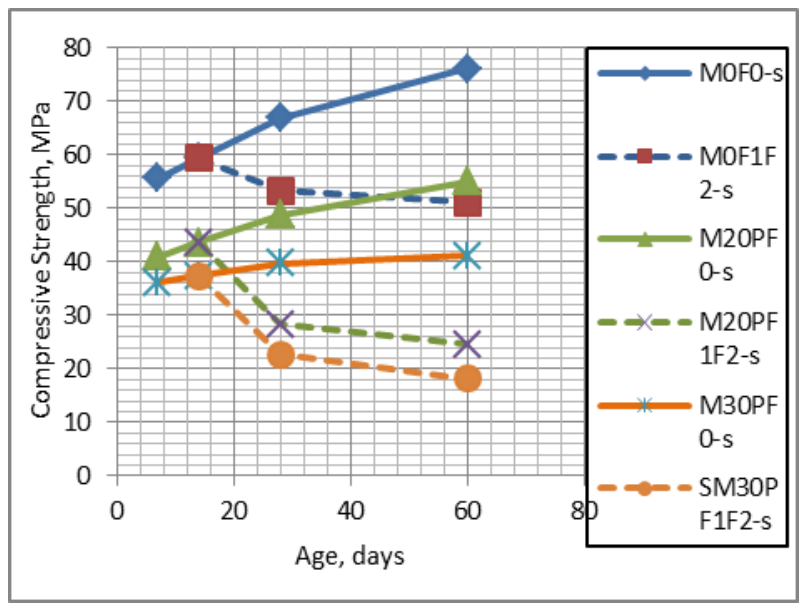

Fig. 5. Compressive strength variations of mixes $\mathrm{M}_{0}, \mathrm{M}_{20 \mathrm{P}}$ and $\mathrm{M}_{30 \mathrm{P}}$ for sealed specimens when being exposed to different freezing and thawing exposures

When making comparisons between F0, F1 and F2, for water-cured mix $\mathrm{M}_{20 \mathrm{P}}$, the reductions in strength will be 
28 and 55 percent for 50 and 100 cycles, respectively. For 30 percent replacement, mix $\mathrm{M}_{30 \mathrm{p}}$; these reductions will be 20 and 51 percent for 50 and 100 cycles respectively. Moreover, when making comparisons between mixes $\mathrm{M}_{0}$ and $\mathrm{M}_{20 \mathrm{P}}$, the reductions in compressive strength will be 42 and 55 percent for 50 and 100 cycles, respectively. For mixes $\mathrm{M}_{0}$ and $\mathrm{M}_{30 \mathrm{P}}$; these reductions will be 50 and 64 percent for 50 and 100 cycles, respectively. The last comparison leads to the conclusion that the high water absorption of Porcelanite is the reason for the higher deterioration caused by freezing and thawing cycles.

\section{Conclusions}

1. In the present work, the F1 and F2 (50 and 100 cycles of freezing and thawing respectively) exposures seem effective enough to investigate the behavior of internally cured concrete.

2. The internal curing does not enhance the concrete resistance to freezing and thawing exposures F1 and F2 and that may be due to:

a. The standard method of test (ASTM C666) stipulated that specimens shall be cured for 14 days in water prior to testing and such period is not enough for concrete with low permeability (high performance concrete) to be saturated. Therefore, the results of mix $\mathrm{M}_{0}$ (without fine aggregate replacement) showed almost the same rate of reduction for both water-cured and sealed specimens.

b. Using saturated agents has increased the moisture content of concrete and makes it more vulnerable to deterioration resulted from frost action.

3. Sealed specimens for all investigated mixes showed lower reductions in strength than water-cured ones. The lesser water contents of these mixes may be the reason for that behavior.
4. Higher water absorption of Porcelanite than limestone dust caused higher deterioration by freezing and thawing cycles.

\section{References}

1. V. Penttala, F. Al-Neshawy, Cement and Concrete research, 32, No. 9 (2002)

2. T. Ohta, Proc. Second Canada/Japan Workshop on Low Temperature Effects on Concrete (1991)

3. P. Mehta, P. Monteiro, Concrete microstructure, properties, and materials (Indian Concrete Institute, 1997)

4. J. Marchand, R, Pleau, R. Gange, Mat. Sci. Conc. (1995)

5. M. Pigeon, C., Talbot, J., Marchand, H. Hornain, Cem. Conc. Res. 26, 10 (1996)

6. S. Jacobsen, J., Marchand, H. Hornain, Cem. Conc. Res., 25, 8 (1995)

7. IQS No. 5, COSQC, Iraq (1984) (in Arabic)

8. IQS No. 45, COSQC, Iraq (1984) (in Arabic)

9. ASTM C1240-15, Annual Book of ASTM Standards, USA (2015)

10. BS EN 12390- P: 3, British Standard Institution, UK (2002)

11. ASTM C666-15, Annual Book of ASTM Standards, USA (2015)

12. T. Rønning, Ph.D. Thesis, Nor. Inst. Tech. (2001)

13. A. M. Neville, Properties of concrete, (Prentice Hall, UK, 2011)

Table 1. Compressive strength results for all mixes at different freezing and thawing exposures for water-cured and sealed specimens

\begin{tabular}{|c|c|c|c|c|c|c|c|c|c|c|}
\hline \multirow{4}{*}{ Mix } & \multicolumn{10}{|c|}{ Compressive Strength of Concrete Mixes, MPa, for Different Exposures at Ages: } \\
\hline & \multicolumn{5}{|c|}{ for water-cured specimens } & \multicolumn{5}{|c|}{$\begin{array}{c}\text { for sealed specimens } \\
\end{array}$} \\
\hline & \multicolumn{3}{|c|}{ F0 } & \multirow{2}{*}{$\begin{array}{l}\text { F1-50 } \\
\text { cycles }\end{array}$} & \multirow{2}{*}{$\begin{array}{l}\text { F2-100 } \\
\text { cycles }\end{array}$} & \multicolumn{3}{|c|}{ F0 } & \multirow{2}{*}{$\begin{array}{l}\text { F1-50 } \\
\text { cycles }\end{array}$} & \multirow{2}{*}{$\begin{array}{c}\text { F2 -100 } \\
\text { cycles }\end{array}$} \\
\hline & $7 \mathrm{~d}$ & $28 \mathrm{~d}$ & $60 \mathrm{~d}$ & & & $7 \mathrm{~d}$ & $28 \mathrm{~d}$ & $60 \mathrm{~d}$ & & \\
\hline $\mathrm{M}_{0}$ & 67.3 & 76.6 & 82.2 & 61.0 & 55.0 & 55.7 & 67.0 & 76.1 & 53.3 & 51.2 \\
\hline $\mathrm{M}_{20 \mathrm{~L}}$ & 62.5 & 67.4 & 69.1 & 40.1 & 30.3 & 52.3 & 54.1 & 61.2 & 37.5 & 30.1 \\
\hline $\mathrm{M}_{30 \mathrm{~L}}$ & 60.1 & 64.7 & 67.7 & 37.7 & 27.8 & 50.0 & 52.1 & 60.1 & 31.9 & 26.6 \\
\hline $\mathrm{M}_{20 \mathrm{P}}$ & 41.2 & 49.3 & 55.0 & 35.5 & 24.7 & 41.0 & 48.8 & 55.1 & 28.3 & 24.6 \\
\hline $\mathrm{M}_{30 \mathrm{P}}$ & 34.9 & 38.1 & 40.1 & 30.3 & 19.8 & 36.2 & 39.7 & 41.2 & 22.7 & 18.1 \\
\hline
\end{tabular}

